\title{
An Exploratory, Observational Cohort Study on the Dynamics of Heparin Binding Protein in Cardiothoracic Surgery Using Cardiopulmonary Bypass
}

\author{
Niklas Sterner \\ Skanes universitetssjukhus Lund \\ Jane Fisher \\ Lund University: Lunds Universitet \\ Louise Thelaus \\ Lund University: Lunds Universitet
}

Carolin Ketteler

Lund University: Lunds Universitet

Špela Lemež

Lund University: Lunds Universitet

Alain Dardashti

Skanes universitetssjukhus Lund

Johan Nilsson

Skanes universitetssjukhus Lund

Adam Linder

Skanes universitetssjukhus Lund

Igor Zindovic ( $\nabla$ igor.zindovic@med.lu.se )

Department of Cardiothoracic Surgery Skåne University Hospital SE-221 85 Lund, Sweden https://orcid.org/0000-0002-6017-2555

\section{Research}

Keywords: Heparin-binding protein, Cardiothoracic surgery, Cardiopulmonary bypass, biomarker, postoperative infections

Posted Date: September 16th, 2020

DOI: https://doi.org/10.21203/rs.3.rs-74892/v1

License: (c) (i) This work is licensed under a Creative Commons Attribution 4.0 International License. Read Full License 
Page $2 / 26$ 


\section{Abstract}

\section{Background}

Surgical trauma and cardiopulmonary bypass (CPB) cause an inflammatory response, difficult to differentiate from postoperative infections. Heparin-binding protein (HBP) is released from neutrophils and has been shown to predict infection-related organ dysfunction and disease progression to severe sepsis. In order to explore the potential of HBP as a biomarker for postoperative infections and asess possible confounding effects of concomitant medications, this study aimed to investigate the pre-, intraand postoperative dynamics of HBP in cardiac surgery with CPB.

\section{Methods}

Thirty patients undergoing cardiac surgery with CPB were included, of which 15 underwent coronary artery bypass grafting (CABG) surgery and 15 underwent complex procedures with longer CPB duration. Ten patients undergoing lung surgery without CPB were also included as a conventional surgery reference group. HBP was measured at nine different perioperative time points.

\section{Results}

Our results showed that HBP levels were not affected by surgical trauma by itself. An increase in HBP levels was observed immediately following heparin administration and further increased during CPB. Prior to protaminization, we measured higher peak HBP-levels in the complex group (345.7 (287.8-472.6) $\mathrm{ng} / \mathrm{mL}$ ) compared with the CABG group (152.7 (85.3-204.0) $\mathrm{ng} / \mathrm{mL}, p<0.001)$. HBP decreased rapidly following cessation of $\mathrm{CPB}$ and simultaneous protamine administration. Delay of protamine administration revealed that protamine, and not the cessation of CPB is primarily responsible for the rapidly reduced HBP concentration. At the arrival to the ICU, the median HBP levels were 24.8 (15.6-38.1) $\mathrm{ng} / \mathrm{mL}$ for CABG patients compared with 50.5 (36.5-104.6) $\mathrm{ng} / \mathrm{mL}$ for complex surgery patients $(p=0.004)$. One day after surgery, HBP levels in all three groups were below the proposed cutoff of 30 $\mathrm{ng} / \mathrm{mL}$, previously found to predict development of organ dysfunction during infection, while other biomarkers for infections remained elevated.

\section{Conclusions}

HBP levels are elevated by administration of heparin and the use of CPB but reduced by protamine administration. At postoperative day one, HBP levels were below the threshold for infection with organ dysfunction, indicating that postoperative HBP measurement may be a better screening tool for postoperative infections than other biomarkers of infections that remain elevated after surgery.

\section{Background}

Cardiac surgery using cardiopulmonary bypass (CPB) induces an acute phase inflammatory reaction including complement activation and secretion of proinflammatory cytokines, such as interleukin (IL)-1 $\beta$, 
IL-6, IL-10 and tumor necrosis factor a (1). An excessive production and release of cytokines can provoke tissue injury which can result in organ dysfunction (2). Surgical trauma and contact with the nonphysiological surfaces of the extracorporeal circuit, endotoxemia, ischemia and reperfusion injury are all stimuli for inflammatory response (3).

The release of inflammatory factors is associated with postoperative complications including increased risk of postoperative infections (4-7). In turn, sepsis is associated with increased rates of postoperative mortality, prolonged hospital stay, and increased health care costs (8). Therefore, early detection of infections in patients with risk of developing severe disease with organ dysfunction remains crucial. However, in clinical practice, there is no accurate tool to differentiate immediate postoperative inflammation from postoperative infections as most inflammatory markers are elevated by the procedure itself (9).

Heparin binding protein (HBP), also known as CAP37 or azurocidin, is a multifunctional, inactive serineprotease homologue (10). It is stored in azurophilic granules and secretory vesicles of neutrophils, released upon stimulation, and is able to recruit and activate monocytes, mobilize $T$ cells and to induce detachment and homotypic aggregation of endothelial cells $(7,11)$. Furthermore, HBP has been shown to play a key role in inducing vascular leakage by mediating increased capillary permeability (12). Previous studies have shown HBP to be an early indicator of infection-related organ dysfunction, a strong predictor of disease progression to severe sepsis and HBP levels above $30 \mathrm{ng} / \mathrm{mL}$ have been shown to be predictive of infection with organ dysfunction (13).

Cardiopulmonary bypass induces neutrophil activation $(1,3)$ and Pesonen et a/ recently showed that HBP is increased during cardiac surgery with CPB (14). However, the postoperative dynamics of HBP and the effects of concomitantly administered heparin and protamine were not investigated. High postoperative HBP concentration due to the inherent neutrophil activation following surgery might interfere with its usefulness as a marker of postoperative infection and for this reason, it is important to establish when HBP concentration normalizes, if the length of surgery could affect its levels and dynamics, and if the concentrations are affected by the administration of medications such as heparin and protamine.

Therefore, in order to evaluate the potential of HBP as a marker for postoperative infections, the aim of this study was to investigate the changes of HBP levels at nine pre-defined time-points before, during and after cardiac surgery using CPB.

\section{Methods}

\section{Study design}

This was a single center, prospective, observational study comparing serial plasma HBP measurements in three groups. The first group consisted of patients undergoing elective coronary artery bypass grafting (CABG) surgery and the second group were patients undergoing complex cardiac surgery. In order to compare the first two groups to a cohort of patients exposed to significant surgical trauma but without 
administration of heparin and the use of CPB, a third group of patients undergoing lung surgery via thoracotomy was included as a reference group. An additional group of patients undergoing CABG surgery were included post hoc for specific analyses of the effect of heparin and protamine on HBP concentration.

The study included patients undergoing cardiothoracic surgery at Skåne University Hospital in Lund, between May 2019 and January 2020. Patients over the age of 18 undergoing elective surgery were eligible for enrollment in the study unless they met any of the exclusion criteria: preoperative treatment with antibiotics or low molecular weight heparin or having a preoperative C-reactive protein (CRP) > $10 \mathrm{mg} / \mathrm{L}$. Additional patients were specifically enrolled post hoc for analyses of heparin and protamine effect on HBP release. The study subjects were not consecutively recruited but were included when resources for sample collection and handling were available.

Concentrations of HBP at the pre-defined time points were regarded as our primary end points.

In this study, complex surgery was defined as surgery with an expected CPB duration of $>120 \mathrm{~min}$. We defined in-hospital mortality as any death during hospital stay. Cardiac failure was defined as requirement of inotropes for more than 24 hours postoperatively, myocardial infarction was defined as ST-elevation on EKG or a postoperative CKMB level of $>50 \mathrm{mg} / \mathrm{L}$. Stroke was defined as clinical loss of neurologic function confirmed by $\mathrm{CT}$ and an infection was considered verified when microbiologically and/or radiologically confirmed with positive cultures from the site of infection.

\section{Surgical procedures}

All patients in the cardiothoracic surgery group received standard anesthetic treatment according to department guidelines. This included diprivan and a volatile anesthetic agent (isoflurane or sevoflurane) throughout the procedure with the supplement of fentanyl when needed. If a neuromuscular blocking agent was required, rocuronium was used. All patients who underwent lung surgery received similar anesthetic treatment as the cardiac surgical patients, with the addition of epidural injection (mepivakain; $10 \mathrm{mg} / \mathrm{mL}$, adrenaline; $5 \mu \mathrm{g} / \mathrm{mL}$; Aspen Pharma) followed by an infusion (bupivacaine; $1 \mathrm{mg} / \mathrm{mL}$, Fentanyl; $2 \mu \mathrm{g} / \mathrm{mL}$, adrenaline $2 \mu \mathrm{g} / \mathrm{mL}$; Apotek Produktion \& Laboratorier AB). The cardiac surgical procedures included standard median sternotomy followed by CPB and intermittent cold blood cardioplegic arrest. The complex group included a variety of aortic procedures with the exception of one patient, who received a left ventricular assist device (Heartmate III). All lung surgery in this study was performed via anterolateral thoracotomy. The CPB system consisted of non-coated polyvinyl chloride and silicone tubing, a Stöckert S5 roller pump, a hard-shell open venous reservoir, and an FX25 Terumo oxygenator. All patients undergoing cardiac surgery were heparinized to an activated clotting time (ACT) above $480 \mathrm{~s}$ before the initiation of CPB. An HMS Hepcon device was used to measure heparin concentration and ACT during $\mathrm{CPB}$ and to determine the amount of protamine to neutralize the heparin before the cessation of CPB. As perioperative infection prophylaxis, CABG patients were given a combination of either cloxacillin or clindaymcin and teicoplanin, while patients undergoing complex 
procedures received imipenem/cilastatin and teicoplanin and those undergoing lung surgery were administered cefuroxim. Routinely, antibiotic treatment was terminated 24 hours postoperatively.

\section{Sample collection}

Blood samples were collected at the following time points; at anesthesia induction; before heparin administration and 5 min after heparin administration; 5 min after the start of CPB; before ending CPB prior to administration of protamine; 5 min after protamine administration; at ICU arrival; one day postsurgery and 3-5 days post-surgery. For the additional five patients, added to specifically investigate the effects of heparin and protamine, we delayed protamine reversal for 5 minutes after termination of CPB and collected an additional sample 5 min after termination of CPB but prior to protamine reversal. Before and after surgery, CPB samples were collected from the radial arterial line. During CPB, blood samples were drawn from the arterial line of the extracorporeal circuit. Postoperative samples were collected using the central venous line. The blood samples were centrifuged for $10 \mathrm{~min}$ at $4400 \mathrm{xg}$, and plasma was separated and stored at $-80^{\circ} \mathrm{C}$.

\section{ELISA of inflammatory markers}

Plasma HBP was analyzed in duplicate using an HBP microtiter plate enzyme-linked immunosorbent assay (ELISA) (Axis-Shield Diagnostics, Dundee, United Kingdom). Recommended dilution of 1:40 for plasma samples was used unless samples were outside the range of the standard curve, in which case the samples were further diluted to 1:400.

In addition, we determined whether the medications that the patient received could interfere with the detection of HBP by the assay. The ELISA has been tested by the manufacturer in the presence of heparin up to 16.3 units $(\mathrm{U}) / \mathrm{mL}$, which is far higher than the target value of $3.5 \mathrm{U} / \mathrm{mL}$ in patients on $\mathrm{CPB}$, and they reported no interference with detection of HBP.

Protamine and heparin-protamine complexes have not been tested by the manufacture. To test the effect of protamine we used plasma samples with low, medium and high concentrations of HBP from a previously described cohort of sepsis patients (Additional Table 1) (15). We spiked the plasma with protamine $(40 \mu \mathrm{g} / \mathrm{mL})$ or equal volume of phosphate buffered saline (PBS; Sigma). In an additional set of plasma samples, we simultaneously added heparin $(3.5 \mathrm{U} / \mathrm{mL}$; LEO Pharma $\mathrm{AB})$ and protamine $\left(40 \mu \mathrm{g} / \mathrm{mL}\right.$; LEO Pharma $\mathrm{AB}$ ) and incubated at $37^{\circ} \mathrm{C}$ for 5 minutes to allow a heparin-protamine complex to form. We analyzed the samples by HBP ELISA at a 1:40 dilution according to the manufacturer's directions and calculated the proportion of HBP detected. 
Table 1

Pre- and intraoperative characteristics of the study population

\begin{tabular}{|c|c|c|c|c|c|}
\hline Characteristic & $\begin{array}{l}\text { Reference group } \\
(n=10)\end{array}$ & $P^{1}$ & $\begin{array}{l}\text { CABG } \\
(n=15)\end{array}$ & $P^{2}$ & $\begin{array}{l}\text { Complex } \\
(n=15)\end{array}$ \\
\hline \multicolumn{6}{|l|}{ Preoperative data } \\
\hline Age & $76(64-76)$ & 0.991 & $\begin{array}{l}67(59- \\
73)\end{array}$ & 0.991 & $\begin{array}{l}68(51- \\
76)\end{array}$ \\
\hline Male gender & $6(60)$ & 0.999 & $11(73)$ & 0.991 & $8(53.3)$ \\
\hline Hypertension & $4(40)$ & 0.999 & $8(53)$ & 0.966 & $12(80)$ \\
\hline NYHA class & $10(100)$ & NA & $15(100)$ & 0.946 & $13(86.7)$ \\
\hline I & $0(0)$ & & $0(0)$ & & $1(6.7)$ \\
\hline II & $0(0)$ & & $0(0)$ & & $0(0)$ \\
\hline III & $0(0)$ & & $0(0)$ & & $1(6.7)$ \\
\hline \multicolumn{6}{|l|}{ IV } \\
\hline COPD & $1(10)$ & 0.991 & $0(0)$ & NA & $0(0)$ \\
\hline Diabetes mellitus & $0(0)$ & 0.698 & $5(33,3)$ & 0.932 & $1(6.7)$ \\
\hline PVD & $0(0)$ & NA & $0(0)$ & NA & $0(0)$ \\
\hline Previous Stroke & $0(0)$ & NA & $0(0)$ & 1.000 & $1(6.7)$ \\
\hline History of smoking & $5(50)$ & 0.999 & $6(40)$ & 1.000 & $6(40)$ \\
\hline Immunosuppressants & $0(0)$ & NA & $0(0)$ & NA & $0(0)$ \\
\hline Steroids & $1(10)$ & 0.991 & $0(0)$ & 1.000 & $1(6.7)$ \\
\hline Preoperative CRP (mg/L) & $2.1(0-3.1)$ & 0.842 & $0.7(0-1)$ & 0.749 & $1(0-3.8)$ \\
\hline Preoperative WBC $\left(10^{9}\right.$ cells/L) & $6(5.75-7.25)$ & 0.932 & $\begin{array}{l}5.9(5.4- \\
6.6)\end{array}$ & 0.932 & $\begin{array}{l}7.1(6.2- \\
8.1)\end{array}$ \\
\hline \multicolumn{6}{|l|}{ Intraoperative data } \\
\hline Operating time (min) & $116(70-183)$ & 0.154 & $\begin{array}{l}170(147- \\
205)\end{array}$ & $\begin{array}{l}< \\
0.001\end{array}$ & $\begin{array}{l}298(252- \\
352)\end{array}$ \\
\hline CPB time (min) & - & NA & $\begin{array}{l}65(48- \\
97)\end{array}$ & $<.001$ & $\begin{array}{l}162(152- \\
205)\end{array}$ \\
\hline
\end{tabular}

${ }^{1}$ Reference group vs CABG (Kruskal Wallis); ${ }^{2}$ CABG vs Complex (Kruskal Wallis and Mann Whitney U test). Values expressed as numbers (\%) or median (IQR). NYHA, New York heart association; COPD, Chronic obstructive pulmonary disease; PVD, peripheral vascular disease; CRP, C-reactive protein; WBC, white blood cell count; CPB, cardiopulmonary bypass. 


\begin{tabular}{|c|c|c|c|c|c|}
\hline Characteristic & $\begin{array}{l}\text { Reference group } \\
(n=10)\end{array}$ & $P^{1}$ & $\begin{array}{l}\text { CABG } \\
(n=15)\end{array}$ & $P^{2}$ & $\begin{array}{l}\text { Complex } \\
(n=15)\end{array}$ \\
\hline Cross clamp time (min) & - & NA & $\begin{array}{l}42(35- \\
57)\end{array}$ & $\grave{0} 001$ & $\begin{array}{l}97(69- \\
150)\end{array}$ \\
\hline Total heparin dose $\left(\mathrm{U} \times 10^{3}\right)$ & - & NA & $\begin{array}{l}37.5 \\
(32.5-45)\end{array}$ & 0.193 & $\begin{array}{l}45(40- \\
60)\end{array}$ \\
\hline Protamine dose (mg) & - & NA & $\begin{array}{l}250(200- \\
300)\end{array}$ & 0.226 & $\begin{array}{l}250(200- \\
400)\end{array}$ \\
\hline $\begin{array}{l}\text { Postoperative heparin } \\
\text { concentration }(\mathrm{U} / \mathrm{ml})\end{array}$ & - & NA & $0(0-0)$ & 1.000 & $0(0-0)$ \\
\hline \multicolumn{6}{|c|}{$\begin{array}{l}{ }^{1} \text { Reference group vs CABG (Kruskal Wallis); }{ }^{2} \text { CABG vs Complex (Kruskal Wallis and Mann Whitney U } \\
\text { test). Values expressed as numbers (\%) or median (IQR). NYHA, New York heart association; COPD, } \\
\text { Chronic obstructive pulmonary disease; PVD, peripheral vascular disease; CRP, C-reactive protein; } \\
\text { WBC, white blood cell count; CPB, cardiopulmonary bypass. }\end{array}$} \\
\hline
\end{tabular}

We measured the concentrations of IL-6 and IL-8 and Myeloperoxidase (MPO), diluted to recommended concentrations in plasma samples using Quantikine ELISA kits for each marker (Bio Techne).

\section{Ex vivo whole blood stimulation}

Whole blood was drawn from healthy donors or from CABG patients prior to heparin administration, and EDTA was used as the anticoagulant. Whole blood from healthy donors was stimulated for 5-30 minutes with a known inducer of neutrophil activation and HBP release, N-Formyl-methionyl-leucyl-phenylalanine (FMLP; Sigma; $500 \mathrm{nM}$ ) (16). Healthy FMLP-stimulated samples and unstimulated CABG patients samples were also treated with either heparin $(3.5 \mathrm{U} / \mathrm{mL})$, protamine $(40 \mu \mathrm{g} / \mathrm{mL})$ or heparin-protamine complex $\left(3.5 \mathrm{U} / \mathrm{mL}\right.$ heparin and $40 \mu \mathrm{g} / \mathrm{mL}$ protamine co-incubated at $37^{\circ} \mathrm{C}$ for 5 minutes prior to stimulation) in order to determine if heparin and protamine had any direct effect on neutrophil activation and HBP release. After each incubation time, $100 \mu \mathrm{L}$ of blood was centrifuged at $2000 \mathrm{xg}$ for 10 minutes and plasma was removed and analyzed by HBP ELISA.

\section{Flow cytometry}

After incubation with the stimulatory agents described above, $50 \mu \mathrm{L}$ of whole blood was fixed immediately with $1 \mathrm{~mL}$ of one step fix-lyse solution (Thermo Fisher) for 30 minutes. Fixed samples were centrifuged twice at $500 \mathrm{xg}$ for $5 \mathrm{~min}$ and washed with PBS followed by resuspension in $50 \mu \mathrm{L}$ of PBS. Fixed samples were incubated with $5 \mu \mathrm{L}$ phycoerythrin (PE)-conjugated mouse anti-human CD11b antibody (BD Biosciences) for 15 minutes and washed once with PBS. They were then analyzed on a BD Accuri C6 system. Samples were gated using forward scatter (FSC) and side scatter (SSC) of the neutrophil population and the median PE intensity of this population was recorded. 
EA.hy926 immortalized human endothelial cells (American Type Culture Collection) were seeded in 6-well plates and grown to confluence in Dulbecco's Modified Eagle's Medium (DMEM; Gibco) supplemented with $10 \%$ fetal bovine serum (FBS; Gibco). Before treating cells, they were washed with sterile PBS. Cells were first treated with human recombinant HBP (Axis-Shield) at a concentration of $400 \mathrm{ng} / \mathrm{mL}$ in serumfree DMEM for $20 \mathrm{~min}$. In some wells, a 20uL aliquot of supernatant was removed and saved for analysis and then, heparin (LEO Pharma AB) was added to the wells to a final concentration of $3.5 \mathrm{IU} / \mathrm{mL}$. Five min after cells were treated with heparin, the supernatant was removed and saved for analysis.

Cells were fixed at three different stages of the experiment: 1) before addition of HBP, 2) 20 min after HBP and 3) $5 \mathrm{~min}$ after heparin. Then chemiluminescence imaging of cells (CLIC) was used to quantify the binding of HBP to the endothelial cell surface (17). Cells were fixed with $4 \%$ paraformaldehyde (PFA) for 60 min in room temperature, and washed twice with PBS, Cells were not permeabilized, so only surfacebound HBP was detected. Cells were then blocked with Tris buffered saline (TBS; Sigma Aldrich) with 5\% goat-serum (BioWest) for one hour at room temperature, then incubated overnight with shaking at $4^{\circ} \mathrm{C}$ with rabbit-anti-HBP antiserum (12), 1:7000) diluted in blocking solution. The following day, cells were washed four times in TBS for three min on shaker followed by incubation with anti-rabbit lgG horseradish peroxidase-linked antibody (Cell signaling technology, 1:7000) diluted in blocking solution for two hours at room temperature. Cells were washed as above and then incubated with enhanced chemiluminescence (ECL) substrate (SuperSignal West Pico Chemiluminescent Substrate; Pierce; prepared according to the manufacturer's directions) for 2-5 min. The cell plate was imaged in ChemiDoc MP imaging system (Biorad), and images were taken using the Chemiluminescence application "Chemi Hi Sensitivity" with 20 s of exposure time. Images were analyzed using Fiji (18) and an area of interest (AOI) was chosen. The AOI was same for all wells in all images and corresponded to about $60 \%$ of the size of the well and placed in the center of the well. The Integrated density values (IntDen) were recorded for each well.

All collected supernatants were centrifuged in $14000 x g$ for 10 min and then analyzed with HBP ELISA as described above.

\section{Statistical analysis}

Categorical variables were expressed as numbers and percentages. Proportions were compared using the chi-square test. Fisher's exact test was used when the number of cases was less than 5 . Independent, non-parametric, continuous variables were presented as medians and interquartile ranges (IQR) and were evaluated using the Kruskal-Wallis test to identify significant differences between the three groups. If significant, Mann-Whitney $\mathrm{U}$ test was used to analyze the difference between the specific groups. For related samples analysis we used the Wilcoxon signed rank test. One-Way Analysis of Variance (ANOVA) were used for HBP quantification on cell surface and in supernatant. Statistical analyses were performed using standard software (SPSS IBM Corp. Released 2017. IBM SPSS Statistics for Mac, Version 26. Armonk, NY: IBM Corp) and graphs were created using GraphPad Prism version 8.3.1. A $p$-value $<0.05$ was considered statistically significant and all $p$-values were adjusted for multiple comparisons using the Holm-Šídák method. Data from in vitro experiments was analyzed using parametric tests (t-test for two groups or one-way ANOVA for three or more groups). 


\section{Results}

\section{Study population}

Between May 2019 and Feb 2020, a total of 49 patients were screened for enrollment in the study of which nine were excluded due to surgery being postponed (Fig. 1). In all, we included 15 patients who underwent elective $C A B G$ surgery (CABG surgery group) and 15 patients who underwent elective aortic procedures except for one, who received a Heartmate III (complex surgery group). The reference group consisted of ten patients undergoing elective lung surgery via anterolateral thoracotomy.

\section{Baseline and intraoperative data}

Baseline and intraoperative data of the study population are presented in Table 1 and were similar between the groups, with the exception of the duration of CPB (65 (48-97) min vs 162 (152-205) min, $p$ $<0.001)$ and cross clamping (42 (35-57) min vs $97(69-150)$ min, $p<0.001)$ being significantly shorter in the CABG group compared to the complex group.

\section{Postoperative data, complications and mortality}

There were no between group differences in rates of postoperative complications (Table 2). CABG patients had a peak CRP of 131 (98-207) mg/L compared to 189 (147-231) mg/L in the complex group $(p=0.710)$ and $77.5(35-176.5) \mathrm{mg} / \mathrm{L}$ in patients undergoing lung surgery ( $p$ vs $C A B G=0.572)$. Peak white blood cell (WBC) count was $12(9-14) \times 10^{9} / \mathrm{L}$ in the CABG group vs $14(13-19) \times 10^{9} / \mathrm{L}$ in complex patients $(p=0.181)$. One patient in the complex group suffered an intraoperative rupture of the aorta with excessive bleeding and prolonged surgery resulting in postoperative heart failure requiring the use of an intra-aortic balloon pump and later extracorporeal membrane oxygenation (ECMO). The HBP values for this study subject remained elevated postoperatively, with an HBP concentration of $372.7 \mathrm{ng} / \mathrm{mL}$ on postoperative day one and $46.4 \mathrm{ng} / \mathrm{mL}$ post-operative day three, while the patient was still on ECMO. Moreover, one patient in the complex group received an internal left ventricular assist device (Heartmate III). The HBP values for this study subject were $49.7 \mathrm{ng} / \mathrm{mL}$ at ICU arrival, $23.6 \mathrm{ng} / \mathrm{mL}$ at post-operative day one and $14.8 \mathrm{ng} / \mathrm{mL}$ on post-operative day three. 
Table 2

Postoperative characteristics of the study population presented by group.

\begin{tabular}{|c|c|c|c|c|c|}
\hline Characteristic & $\begin{array}{l}\text { Reference } \\
\text { group } \\
(n=10)\end{array}$ & $p^{1}$ & $\begin{array}{l}\text { CABG } \\
(n=15)\end{array}$ & $p^{2}$ & $\begin{array}{l}\text { Complex } \\
(n=15)\end{array}$ \\
\hline In-hospital mortality & $0(0)$ & NA & $0(0)$ & 1.000 & $1(6.7)$ \\
\hline ICU stay (h) & $4(2.75-8.75)$ & $\begin{array}{l}<.001 \\
0 .\end{array}$ & $21(19-22)$ & 0.215 & $41(21-48)$ \\
\hline Time on ventilator (h) & $0(0-0)$ & $<.001$ & $4(3-6)$ & 0.586 & $6(4-16)$ \\
\hline Cardiac failure & $0(0)$ & NA & $0(0)$ & 1.000 & $1(6.7)$ \\
\hline Myocardial infarction & $0(0)$ & NA & $0(0)$ & 1.000 & $1(6.7)$ \\
\hline Atrial fibrillation & $0(0)$ & 0.586 & $5(33.3)$ & 0.996 & $8(53.3)$ \\
\hline Stroke & $0(0)$ & NA & $0(0)$ & 1.000 & $1(6.7)$ \\
\hline RRT & $0(0)$ & NA & $0(0)$ & 1.000 & $1(6.7)$ \\
\hline $\begin{array}{l}\text { Re-exploration for } \\
\text { bleeding }\end{array}$ & $0(0)$ & NA & $0(0)$ & 0.996 & $2(13.3)$ \\
\hline Antibiotic treatment & $1(10)$ & 1.000 & $1(6.7)$ & 0.213 & $8(53.3)$ \\
\hline Verified infection & $0(0)$ & NA & $0(0)$ & 0.998 & $3(20)$ \\
\hline Peak CRP (mg/L) & $77.5(35-176.5)$ & 0.572 & $\begin{array}{l}131(98- \\
207)\end{array}$ & 0.710 & $189(147-231)$ \\
\hline Peak WBC $\left(10^{9}\right.$ cells $\left./ \mathrm{L}\right)$ & $10(7.75-14)$ & 0.999 & $12(9-14)$ & 0.181 & $14(13-19)$ \\
\hline Peak Lactate (mmol/L) & $1.3(1.1-1.8)$ & 0.947 & $1.6(1.3-2.0)$ & 0.108 & $2.2(1.7-2.9)$ \\
\hline
\end{tabular}

\section{Biomarker measurements}

HBP levels at the predefined timepoints for the three groups are presented in Table 3 and Fig. 2a. At anesthesia induction, there were no statistically significant differences in HBP levels between the three groups (5.9 (4.0-10.3) $\mathrm{ng} / \mathrm{mL}$ in the CABG group vs $7.6(4.6-13.3) \mathrm{ng} / \mathrm{mL}$ in the complex group $(p=$ $0.960)$ and $7.1(4.2-9.7) \mathrm{ng} / \mathrm{mL}$ in the reference group ( $p$ vs CABG $=0.960)$ ). The administration of heparin caused an increase in HBP levels in both CABG (5.9 (4.0-10.3) ng/mL at baseline to 73.4 (44.9$84.2) \mathrm{ng} / \mathrm{mL}$ post heparin, $p=0.011)$ and complex patients $(7.6(4.6-13.3) \mathrm{ng} / \mathrm{mL}$ at baseline to 78.5 $(72.1-113.0) \mathrm{ng} / \mathrm{mL}$ post heparin, $p=0.011$ ) (Additional Table 2). Compared to complex patients, CABG patients demonstrated significantly lower HBP concentration five minutes after CPB start (48.0 (29.2- 
70.0) vs $77.2(60.5-94.2) \mathrm{ng} / \mathrm{mL}, p=0.032)$, before the cessation of CPB (152.7 (85.3-204.1) vs 345.7 $(287.8-472.6) \mathrm{ng} / \mathrm{mL}, p<0.001), 5 \mathrm{~min}$ after protamine reversal (44.4 (29.8-99.8) vs 109.1 (99.5-209.0) $\mathrm{ng} / \mathrm{mL}, p=0.003)$, and at ICU arrival (24.8 (15.6-38.1) vs $50.5(36.5-104.6) \mathrm{ng} / \mathrm{mL}, p=0.004)$. At arrival to the ICU, patients in the reference group had an HBP concentration of $11.0(9.5-20.0) \mathrm{ng} / \mathrm{mL}$. One day post-surgery, HBP concentration did not differ significantly between the CABG and complex group (12.5 (10.7-19.8) and $18.1(12.2-23.4) \mathrm{ng} / \mathrm{mL}$, respectively $(p=0.359))$. Both groups demonstrated medians and IQRs below the previously established threshold for sepsis of $30 \mathrm{ng} / \mathrm{mL}$ (9) and $3-5$ days postsurgery $(11.3(6.7-13.5)$ vs $14.8(10.9-22.3) \mathrm{ng} / \mathrm{mL}$, in CABG and complex patients respectively ( $p=$ 0.055)) (Fig. 2a). There was a statistically significant correlation between the duration of CPB and measured peak HBP concentration $(r=0.598, p=0.002)$, HBP levels five minutes after protamine reversal $(r=0.539, p=0.006)$, ICU arrival $(r=0.462, p=0.024)$ and $3-5$ days post-surgery $(r=0.655, p=0.001)$ (Fig. 3).

Table 3

HBP concentrations at the pre-defined time points presented by group.

\begin{tabular}{|c|c|c|c|c|c|}
\hline Characteristic & $\begin{array}{l}\text { Reference group } \\
(n=10)\end{array}$ & $p^{1}$ & $\begin{array}{l}\text { CABG } \\
(n=15)\end{array}$ & $p^{2}$ & $\begin{array}{l}\text { Complex } \\
(n=15)\end{array}$ \\
\hline At anesthesia $(\mathrm{ng} / \mathrm{mL})$ & $7.1(4.2-9.7)$ & 0.960 & $5.9(4.0-10.3)$ & 0.960 & $7.6(4.6-13.3)$ \\
\hline Before heparin $(\mathrm{ng} / \mathrm{mL})$ & - & NA & $7.4(5.5-14.3)$ & 0.960 & $\begin{array}{l}10.0(6.7- \\
13.0)\end{array}$ \\
\hline $\begin{array}{l}5 \text { min post heparin } \\
(\mathrm{ng} / \mathrm{mL})\end{array}$ & - & NA & $\begin{array}{l}73.4(44.9- \\
84.2)\end{array}$ & 0.719 & $\begin{array}{l}78.5(72.1- \\
113.0)\end{array}$ \\
\hline $\begin{array}{l}5 \mathrm{~min} \text { after CPB start } \\
(\mathrm{ng} / \mathrm{mL})\end{array}$ & - & NA & $\begin{array}{l}48.0(29.2- \\
70.0)\end{array}$ & 0.032 & $\begin{array}{l}77.2(60.5- \\
94.2)\end{array}$ \\
\hline $\begin{array}{l}\text { Before ending CPB } \\
(\mathrm{ng} / \mathrm{mL})\end{array}$ & - & NA & $\begin{array}{l}152.7(85.3- \\
204.0)\end{array}$ & $<.001$ & $\begin{array}{l}345.7(287.8- \\
472.6)\end{array}$ \\
\hline $\begin{array}{l}5 \text { min post protamine/ } \\
(\mathrm{ng} / \mathrm{mL})\end{array}$ & - & NA & $\begin{array}{l}44.4(29.8- \\
99.8)\end{array}$ & 0.003 & $\begin{array}{l}109.1(99.5- \\
209.0)\end{array}$ \\
\hline ICU arrival (ng/mL) & $11.0(9.5-20.0)$ & 0.064 & $\begin{array}{l}24.8(15.6- \\
38.1)\end{array}$ & 0.004 & $\begin{array}{l}50.5(36.5- \\
104.6)\end{array}$ \\
\hline $\begin{array}{l}1 \text { day post-surgery } \\
(\mathrm{ng} / \mathrm{mL})\end{array}$ & - & NA & $\begin{array}{l}12.5(10.7- \\
19.8)\end{array}$ & 0.359 & $\begin{array}{l}18.1(12.2- \\
23.4)\end{array}$ \\
\hline $\begin{array}{l}3-5 \text { days post-surgery } \\
(\mathrm{ng} / \mathrm{mL})\end{array}$ & - & NA & $\begin{array}{l}11.3(6.7- \\
13.5)\end{array}$ & 0.055 & $\begin{array}{l}14.8(10.9- \\
22.3)\end{array}$ \\
\hline
\end{tabular}

${ }^{1}$ Reference group vs CABG (Kruskal Wallis); ${ }^{2}$ CABG vs Complex (Kruskal Wallis and Mann Whitney U test). Values expressed as numbers (\%) or median (IQR). CPB, cardiopulmonary bypass; ICU, intensive care unit. 
Apart from the measurement of HBP, additional inflammatory markers were measured in order to assess any differences in dynamics during cardiac surgery with CPB (Additional Table 3). IL-6 and IL-8 levels showed a distinctly different pattern from HBP (Fig. 2b). IL-8 was not elevated at any time point during surgery, while IL-6 peaked later then HBP and the drop was slower. MPO concentrations had similar dynamics to HBP with a peak at the cessation of CPB that rapidly dropped after surgery (Fig. 2C). CRP had a delayed response, reaching its peak $3-5$ days post-operatively.

\section{Additional study group}

In the additional study group, one of five patients had an ad hoc off-pump procedure due to the intraoperative discovery of a porcelain aorta. In the other four patients, protamine administration was delayed until five minutes after the cessation of CPB in order to resemble the timing of the sample taken after protamine administration in the remaining patients, and thereby determine whether CPB cessation or protamine are responsible for the drop in HBP. In these patients, the HBP concentration remained elevated five minutes after the cessation of CPB but decreased significantly immediately after protaminization from 285.9 (115.1-388.1) to $69.80(24.8-124.6) \mathrm{ng} / \mathrm{mL}, p=0.043$ (Fig. 4). The off-pump patient had a lower peak HBP $(88.3 \mathrm{ng} / \mathrm{mL} ; 5$ min post heparin) than the CPB patients but in remaining aspects the dynamics resembled the rest of the study group.

\section{Protamine interference in HBP ELISA}

To ensure that the rapid changes in HBP concentration were not due to interference of administered medications with the ELISA assay, we tested protamine-spiked plasma samples of known HBP concentration. We were able to detect $74 \pm 12 \%$ of HBP (Additional Table 1 ) indicating a small level of interference of protamine with the ELISA. However, when plasma samples were spiked with both heparin and protamine to form a heparin-protamine complex, as would be present in our study subjects, $100 \pm 3 \%$ of HBP was detected, indicating no interference with the ELISA. These results were similar regardless of HBP concentration in the sample suggesting that this is not a concentration-dependent effect.

\section{Heparin and protamine effect on neutrophil activation}

To test whether heparin, protamine and heparin-protamine complex affect neutrophil activation, we stimulated whole blood from healthy donors with heparin, protamine and heparin-protamine complex. No difference was seen in HBP release or CD11b intensity in either of the groups (Additional file 1a and 1b). Neutrophil activation was induced with FMLP, a known activator of neutrophils, resulting in more HBP and higher median CD11b intensity than samples without FMLP. These levels were unchanged by the addition of heparin, protamine or heparin-protamine complex indicating that these factors do not affect FMLP-induced neutrophil activation. Additionally, whole blood taken from the five additional patients corresponding to the " 5 minutes before heparin" time point was stimulated with heparin to account for the possibility that neutrophil stimulation due to initial surgical trauma could affect their response. HBP levels and CD11b intensity were also not affected by stimulation with heparin in these samples indicating no direct effect on neutrophil activation or HBP release (Additional file 1c and 1d). 


\section{HBP interaction with the endothelium}

Because heparin did not induce HBP release from neutrophils, we hypothesized that the spike in HBP levels after heparin administration observed in patients was due to release of HBP adsorbed to the endothelium. To test this hypothesis, we added HBP to cultured endothelial cells. After 20 minutes, HBP level in the supernatant decreased from the starting concentration of $400 \mathrm{ng} / \mathrm{mL}$ to $99.4 \pm 10.9 \mathrm{ng} / \mathrm{mL}$, while HBP levels on the endothelial cell surface were increased compared to cells with no HBP $\left(1.0 \times 10^{7}\right.$ $\pm 1.2 \times 10^{6} \mathrm{U}$ vs $\left.5.1 \times 10^{6} \pm 4.3 \times 10^{6} \mathrm{U}\right)$. Five minutes after adding heparin, the HBP level in the supernatant increased significantly to $162.6 \pm 15.4 \mathrm{ng} / \mathrm{mL}(p<0.001)$ and the HBP level on the endothelial cell surface decreased to $1.6 \times 10^{6} \pm 1.3 \times 10^{6} \mathrm{U}$ indicating that heparin released the adsorbed HBP from the cell surface (Fig. $5 a$ and $5 b$ ).

\section{Discussion}

In this prospective, exploratory study we demonstrated that plasma HBP increases due to heparin administration and the stimulation caused by CPB. Furthermore, the HBP concentration decreases immediately after CPB cessation as a result of protamine administration. By the first postoperative day, HBP reaches concentrations below those previously indicated as a threshold for the detection of infections with organ dysfunction.

Cardiac surgery using CPB induces a systemic inflammatory response including neutrophil activation, also leading to endotoxemia, ischemia and reperfusion injury $(1,3)$. Infections occur in $5-21 \%$ of cases after cardiac procedures and have negative effects on surgical outcomes including prolonged hospitalization, development of multiorgan dysfunction and increased hospital mortality (19). Therefore, early detection of post-operative infections is essential in patients undergoing major surgery. In this study, we confirmed that biomarkers commonly used to detect infections (e.g. CRP and WBC) are unspecifically elevated postoperatively, making it hard to separate systemic inflammation caused by surgical trauma from post-operative infections. Therefore, there is a need for a specific and reliable biomarker for early detection of postoperative infections.

To our knowledge, two studies have described HBP levels in cardiac surgery. Pesonen et al showed a 39fold increase in HBP concentration during cardiac surgery with CPB and Pan et al demonstrated that elevated HBP levels after the release of cross-clamp predicted myocardial injury related cardiogenicshock after cardiac surgery $(14,20)$. However, neither study did fully describe the intra-and postoperative dynamics of HBP or investigate whether the administration of heparin and protamine has any effect on HBP levels.

In our study, we showed that the administration of heparin caused a significant increase in HBP in both CABG and complex cardiac surgery patients. Whole blood from both healthy donors and CABG patients did not show a similar increase in HBP concentration when stimulated ex vivo, suggesting that the increase in HBP was not derived from direct stimulation of neutrophils or other blood cells. HBP is a 
highly positively charged molecule that has been shown to interact with negatively charged molecules and receptors, such as the glycocalyx of the endothelium. Therefore, we hypothesized that limited neutrophil activation occurs during the initial surgical trauma, which releases some HBP that binds to negatively charged molecules on the endothelial surface, such as proteoglycans (21). We used cultured endothelial cells to show that HBP adsorbs to the endothelial surface within 20 minutes and is then released within five minutes of adding heparin. We therefore suggest that the administration of high doses of negatively charged heparin competes with the binding of HBP to the negatively charged receptors on the endothelium. HBP is subsequently bound by heparin and released into the blood stream, rendering it detectable by ELISA. Our data indicate that the complex between heparin and HBP is not cleared from the circulation, as HBP levels decrease only after neutralization of heparin by protamine. These proposed mechanisms are summarized in Fig. 6.

Heparin itself has, in both in vitro and in vivo studies, been demonstrated to have beneficial effects in blocking HBP-induced vascular leakage and renal inflammation (21). Therefore, even if heparin induces an HBP elevation its effects are likely blocked by the presence high doses of heparin. This is supported by our finding that, although HBP levels during cardiac surgery with CPB exceed those seen in septic patients, the surgical patients are hemodynamically stable and do not bear any clinical resemblance to patients presenting with septic shock. Although we cannot exclude that HBP has an effect on capillary permeability in this setting, the clinical picture indicates that the HBP released after heparin administration and during CPB lacks its usual biological activity.

After the initial rise five minutes after heparin administration, HBP concentration dropped slightly five minutes after CPB started in CABG patients but not in those undergoing complex surgery. This drop was most likely due to hemodilution of the patients when starting CPB. The CPB circuit of patients undergoing complex surgery is primed with albumin, mannitol and occasionally red blood cells, while it is primed with crystalloids in CABG surgery patients. Crystalloids are ionic salt solutions similar to those commonly used to disrupt ionic charge-charge interactions between molecules, such as the interaction between HBP and heparin $(22,23)$. Therefore, it is likely that the administration of crystalloids induced a partial disruption of the circulating HBP-heparin complex, allowing some HBP to adsorb to the endothelium, resulting in reduced plasma HBP. Contact between blood and the CPB causes a systemic inflammatory response which leads to neutrophil activation and additional neutrophil release. This is the likely reason for the increase of HBP concentration during CPB (24), supported by the finding of a similar increase of MPO, which is released by activated neutrophils (25).

A significant drop in HBP was seen 5 minutes after protamine administration and the cessation of CPB. In the separate group of patients where protamine was delayed until 5 minutes after CPB end, HBP levels remained elevated until protamine was administered, suggesting that protamine, and not the lack of CPB stimulation, is the major cause of the drop in HBP concentration. Ex vivo stimulation of healthy blood with protamine did not block HBP release, suggesting that protamine does not affect the neutrophils themselves. Protamine is a highly positively charged molecule that binds strongly to heparin. We showed that, although protamine interfered slightly with the ELISA, it was not to such extent that this would 
explain the drop in HBP levels, and this interference was reversed in the presence of heparin. Therefore, we speculate that protamine displaces HBP from binding to heparin in the blood, and the free HBP is again able to bind to the negatively charged receptors of the endothelium and eventually to be cleared from the circulation, resulting in a rapid drop in HBP levels (Fig. 6).

At ICU arrival, HBP concentration still differed significantly between the two groups but was below the threshold for infection with organ dysfunction in CABG patients (13). In patients undergoing lung surgery, HBP levels at ICU arrival were significantly lower than in CABG patients indicating that the major mechanism of postoperatively elevated HBP is CPB rather than surgical trauma and that surgical trauma has a limited effect on postoperative HBP values. However, on postoperative day one, HBP concentrations were below $30 \mathrm{ng} / \mathrm{mL}$ in all study subjects, except for the one patient who later died after nine days on ECMO.

In a recent study on patients undergoing cardiac surgery with CPB, Pan et al showed that HBP predicted postoperative cardiogenic shock (20). Interestingly, in the study by Pan et al, mean HBP concentration was $91 \mathrm{ng} / \mathrm{mL}$ after 24 hours and $84 \mathrm{ng} / \mathrm{mL}$ after 48 hours also in cases not complicated by cardiogenic shock. This contradicts our findings with all but one patient having HBP concentrations below $30 \mathrm{ng} / \mathrm{mL}$ on the first postoperative day. Pan et al did not measure pre-operative HBP levels and therefore we cannot put the postoperative HBP levels in relation to preoperative concentrations. The group used a different HBP ELISA kit and without the pre-operative samples we do not know whether the ELISA kit measures higher baseline HBP or is more effected by hemolysis or any of the medications given, which could all affect detected HBP levels. Furthermore, their finding is surprising, considering that patients in the group without cardiogenic shock did not have significant rates of other postoperative complications that might activate neutrophils and considering a previous observation by our research group that the half-life of HBP in the blood is only two minutes (unpublished data).

In current clinical routine, CRP and WBC are used as primary biomarkers for the detection of postoperative infections. However, WBC is unspecifically elevated after surgery, as is CRP, reaching its peak value on the third postoperative day. In this study we could demonstrate that HBP levels significantly decreased already at arrival to the ICU whereas CRP, WBC, IL-6 or IL-8 all peaked at a later time point. MPO had similar dynamics as HBP but was slightly more elevated on post-operative day one and has the downside of not being available for analysis in clinical routine. Therefore, our data suggest that HBP, which is currently available for rapid analysis at our institution and is advancing toward routine clinical use, indeed has the potential of serving as a screening tool for infections after surgery, even after the use of CPB.

We acknowledge that this study has several limitations. First, although this is an exploratory study, the study samples size was small with consequent risk of type II errors. Postoperative samples were not collected consecutively or at completely uniform time points due to logistic considerations. We are aware that the optimal control group would have consisted of patients undergoing off-pump cardiac surgery and we included one such patient in our study. However, at our institution, we do not perform off-pump 
surgery by routine and therefore we used patients undergoing lung surgery via antero-lateral thoracotomy as a reference group. Although the groups are not perfectly comparable, we believe that using a reference group of patients undergoing lung surgery with significant surgical trauma but the absence of CPB was an acceptable substitute. Furthermore, our intention was to always centrifuge the blood samples immediately on collection, but in some cases, centrifugation was delayed up to 20 minutes. We cannot exclude the possibility that this had an effect on the ratio of components in the blood samples. Lastly, we did not test the binding strength for HBP to heparin in the presence or absence of protamine to confirm our suggested mechanism of HBP increase and decrease following heparin and protamine administration as this was beyond of the scope of the current study.

\section{Conclusions}

Plasma levels of HBP are increased by heparin and the use of CPB and reduced by the administration of protamine. By the first postoperative day HBP concentrations in our study were lower than a previously established threshold for prediction of infection-related organ injury, regardless of surgical complexity. Our data indicate that the pro-inflammatory effects of cardiothoracic surgery with CPB affect postoperative HBP to a lesser extent than they affect other infection markers, indicating that HBP should be explored further as a biomarker for prediction of infections in these patients.

\section{Abbreviations}

ACT

Activated clotting time

$\mathrm{AOI}$

Area of interest

CABG

Coronary artery bypass grafting

$\mathrm{Cl}$

Confidence interval

CLIC

Chemiluminescence imaging of cells

COPD

Chronic obstructive pulmonary disease

CPB

Cardiopulmonary bypass

CRP

C-reactive protein

CVI

Cerebral vascular insult

DMEM 
Dulbecco's Modified Eagle's Medium

ECL

Enhanced chemiluminescence

ELISA

Enzyme-linked immunosorbent assay

FMLP

$\mathrm{N}$-Formyl-methionyl-leucyl-phenylalanine

FSC

Forward scatter

HBP

Heparin binding protein

ICU

Intensive care unit

IL

Interleukin

IQR

Interquartile range

MPO

Myeloperoxidase

NYHA

New York Heart Association

PBS

Phosphate buffered saline

PE

Phycoerythrin

PFA

Paraformaldehyde

PVD

Peripheral vascular disease

RRT

Renal replacement therapy

SSC

Side scatter

TBS

Tris buffered saline

WBC

White blood cell

\section{Declarations}




\section{Ethics approval and consent to participate}

The study was approved by the Ethics Committee for Clinical Research at Lund University, Sweden and informed consent was obtained from each study subject included in the prospective study. A separate approval has previously been obtained for ex-vivo stimulation of blood from healthy donors (reference number. 2019-00210 and 2013/728, respectively).

\section{Consent for publication}

Not applicable

\section{Availability of data and material}

The datasets used and/or analyzed during the current study are available from the corresponding author on reasonable request.

\section{Competing interests}

$\mathrm{AL}$ is listed as one of the inventors of a pending patent for HBP as a biomarker in sepsis filed by Hansa Medical. The remaining authors have no competing interests to declare.

\section{Funding}

This study was funded by grants from the Swedish Medical Training and Research Agreement, Olle Dahlbäck's fund and Ehrenberg's memory fund, Tornspiran foundation and Syskonen Lundgren foundation.

\section{Authors' contributions}

The conception and design of the study was made by NS, IZ and AL. NS participated in the acquisition and analysis of the data and produced the first draft of the manuscript together with LT. NS and LT preformed statistical analysis of the data. JF, LT, CK and ŠL participated in acquisition of data by ELISA and planned, preformed and interpreted in vitro and ex vivo experiments. The data was interpreted, and the manuscript critically reviewed for important intellectual content by all mentioned authors. All authors had full access to all study data (including statistical reports and tables) and take responsibility for the integrity of the data and the accuracy of the data analysis. The final version of the manuscript was approved by all authors.

\section{Acknowledgements}

Not applicable.

\section{References}


1. Hill GE. Cardiopulmonary bypass-induced inflammation: is it important?.

2. Cardiothorac Vasc J. Anesth. 1998;12(2 Suppl 1):21-5.

3. Blackwell TS, Christman JW. Sepsis and cytokines: current status. Br J Anaesth. 1996;77(1):110-7.

4. Sawa Y, Shimazaki Y, Kadoba K, Masai T, Fukuda H, Ohata T, et al. Attenuation of cardiopulmonary bypass; derived inflammatory reactions reduces myocardial reperfusion injury in cardiac operations. J Thorac Cardiovasc Surg. 1996;111(1):29-35.

5. Hall RI, Smith MS, Rocker G. The systemic inflammatory response to cardiopulmonary bypass: pathophysiological, therapeutic, and pharmacological considerations. Anesth Analg. 1997;85(4):766-82.

6. Bical OM, Fromes Y, Gaillard D, Fischer M, Ponzio O, Deleuze P, et al. Comparison of the inflammatory response between miniaturized and standard CPB circuits in aortic valve surgery. Eur $\mathrm{J}$ Cardiothorac Surg. 2006;29(5):699-702.

7. Mohri Y, Miki C, Kobayashi M, Okita Y, Inoue M, Uchida K, et al. Correlation between preoperative systemic inflammation and postoperative infection in patients with gastrointestinal cancer: a multicenter study. Surg Today. 2014;44(5):859-67.

8. Facy O, Paquette B, Orry D, Santucci N, Rat P, Rat P, et al. Inflammatory markers as early predictors of infection after colorectal surgery: the same cut-off values in laparoscopy and laparotomy? Int $J$ Colorectal Dis. 2017;32(6):857-63.

9. Ou L, Chen J, Hillman K, Flabouris A, Parr M, Assareh H, et al. The impact of post-operative sepsis on mortality after hospital discharge among elective surgical patients: a population-based cohort study. Crit Care. 2017;21(1):34-

10. Ayala J, Smith A, Farrar D. C-reactive protein levels following cardiac surgery in adults: Eur J Anaest. 2006;23.

11. Linder A, Åkesson P, Inghammar M, Treutiger C-J, Linnér A, Sundén-Cullberg J. Elevated plasma levels of heparin-binding protein in intensive care unit patients with severe sepsis and septic shock. Crit Care. 2012;16(3):R90-R.

12. Ostergaard E, Flodgaard H. A neutrophil-derived proteolytic inactive elastase homologue (hHBP) mediates reversible contraction of fibroblasts and endothelial cell monolayers and stimulates monocyte survival and thrombospondin secretion. J Leukoc Biol. 1992;51(4):316-23.

13. Tapper $\mathrm{H}$, Karlsson A, Mörgelin M, Flodgaard H, Herwald H. Secretion of heparin-binding protein from human neutrophils is determined by its localization in azurophilic granules and secretory vesicles. Blood. 2002;99(5):1785-93.

14. Linder A, Arnold R, Boyd JH, Zindovic M, Zindovic I, Lange A, et al. Heparin-Binding Protein Measurement Improves the Prediction of Severe Infection With Organ Dysfunction in the Emergency Department. Crit Care Med. 2015;43(11):2378-86.

15. Pesonen E, Passov A, Salminen U-S, Ilmakunnas M, Vento A, Aittomäki J, et al. Heparin Binding Protein in Adult Heart Surgery. Ann Thorac Surg. 2019;107(4):1154-9. 
16. Linder A, Christensson B, Herwald H, Björck L, Akesson P. Heparin-Binding Protein: An Early Marker of Circulatory Failure in Sepsis. Clin Infect Dis. 2009;49:1044-50.

17. Di Gennaro A, Kenne E, Wan M, Soehnlein O, Lindbom L, Haeggström JZ. Leukotriene B4- induced changes in vascular permeability are mediated by neutrophil release of heparin-binding protein (HBP/CAP37/azurocidin). FASEB J. 2009;23(6):1750-7.

18. Fisher J, Anas HA, Abu-Humaidan. Using chemiluminescence imaging of cell culture plates (CLIC) for protein quantification. Submitted to Scientific reports 2nd of March 2020. 2020.

19. Schindelin J, Arganda-Carreras I, Frise E, Kaynig V, Longair M, Pietzsch T, et al. Fiji: an open-source platform for biological-image analysis. Nat Methods. 2012;9(7):676-82.

20. Kollef MH, Sharpless L, Vlasnik J, Pasque C, Murphy D, Fraser VJ. The impact of nosocomial infections on patient outcomes following cardiac surgery. Chest. 1997;112(3):666-75.

21. Pan T, Long G-F, Chen C, Zhang H-T, Wang J-X, Ahaskar A, et al. Heparin-binding protein measurement improves the prediction of myocardial injury-related cardiogenic shock. BMC Cardiovasc Disord. 2020;20(1):124.

22. Bentzer P, Fisher J, Kong HJ, Mörgelin M, Boyd JH, Walley KR, et al. Heparin-binding protein is important for vascular leak in sepsis. Int Care Med Exp. 2016;4(1):33.

23. Jayanthi S, Gundampati RK, Kumar TKS. Simple and Efficient Purification of Recombinant Proteins Using the Heparin-Binding Affinity Tag. Curr Protoc Protein Sci. 2017;90:6.16.1-6.

24. Powell AK, Yates EA, Fernig DG, Turnbull JE. Interactions of heparin/heparan sulfate with proteins: Appraisal of structural factors and experimental approaches. Glycobiology. 2004;14(4):17R-30R.

25. Westaby S. Complement and the damaging effects of cardiopulmonary bypass. Ann Thorac Surg. 1983;38(5):321-5.

26. Faymonville ME, Pincemail J, Duchateau J, Paulus JM, Adam A, Deby-Dupont G, et al. Myeloperoxidase and elastase as markers of leukocyte activation during cardiopulmonary bypass in humans. J Thorac Cardiovasc Surg. 1991;102(2):309-17.

\section{Figures}




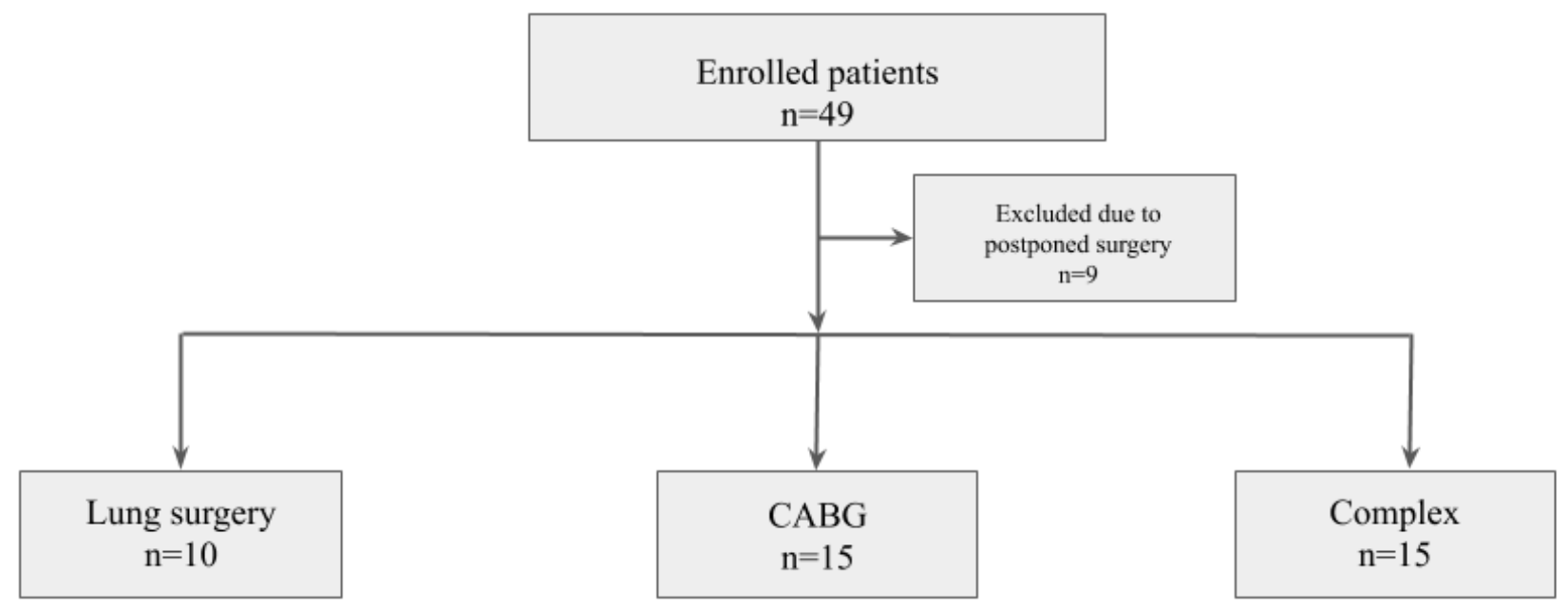

\section{Figure 1}

A flowchart describing the study design and distribution of patients between the reference-, coronary artery bypass grafting (CABG)- and complex surgery group.
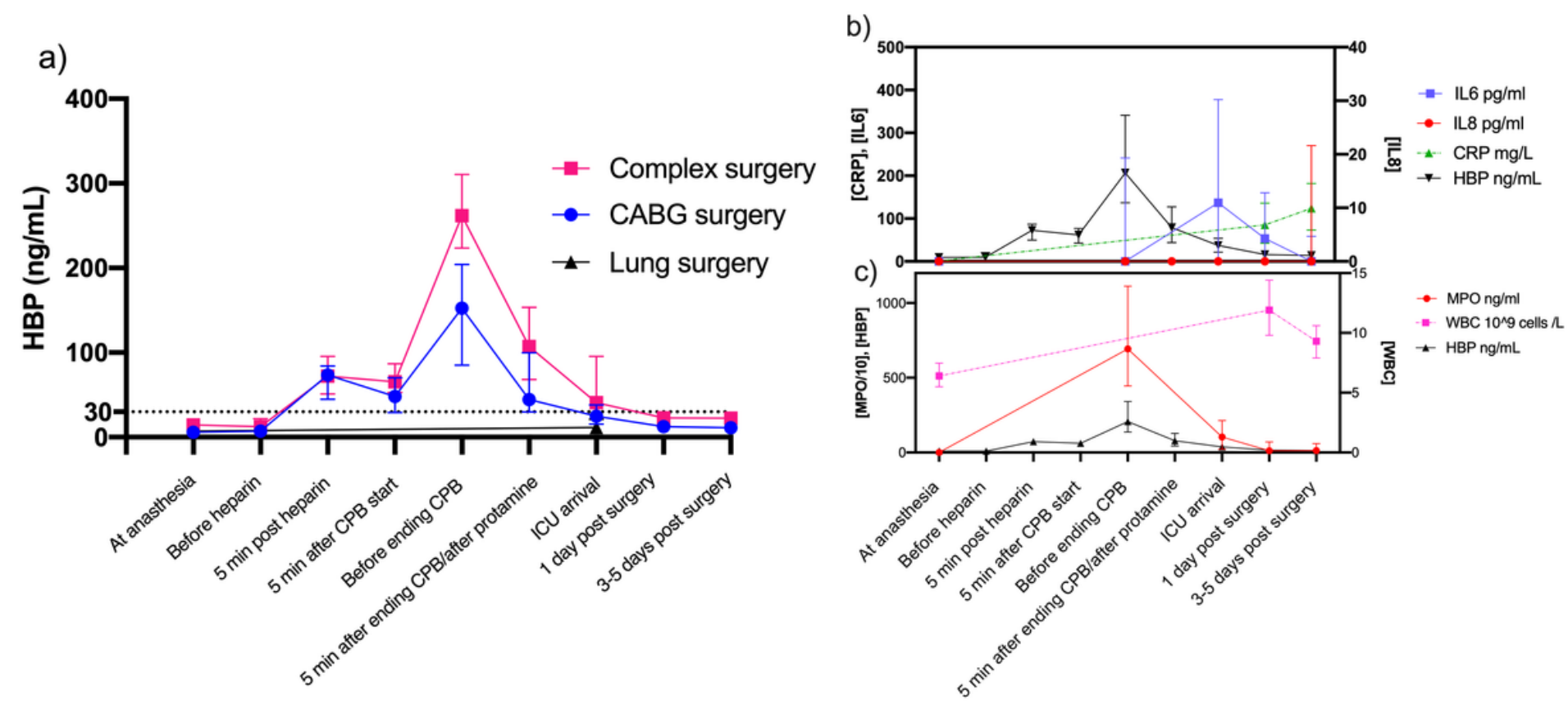

Figure 2 
Dynamics of inflammatory markers during and after surgery. A) Heparin binding protein (HBP) concentrations are presented for each study group as median $+/$ - interquartile range (IQR). Dotted line indicates the threshold used for detection of infection with organ injury $(30 \mathrm{ng} / \mathrm{mL})$. B) Concentrations of the inflammation markers interleukin 6 (IL-6), IL-8 and C-reactive protein (CRP) compared to HBP. C) Concentrations of myeloperoxidase (MPO) and white blood cell count (WBC) compared to HBP.

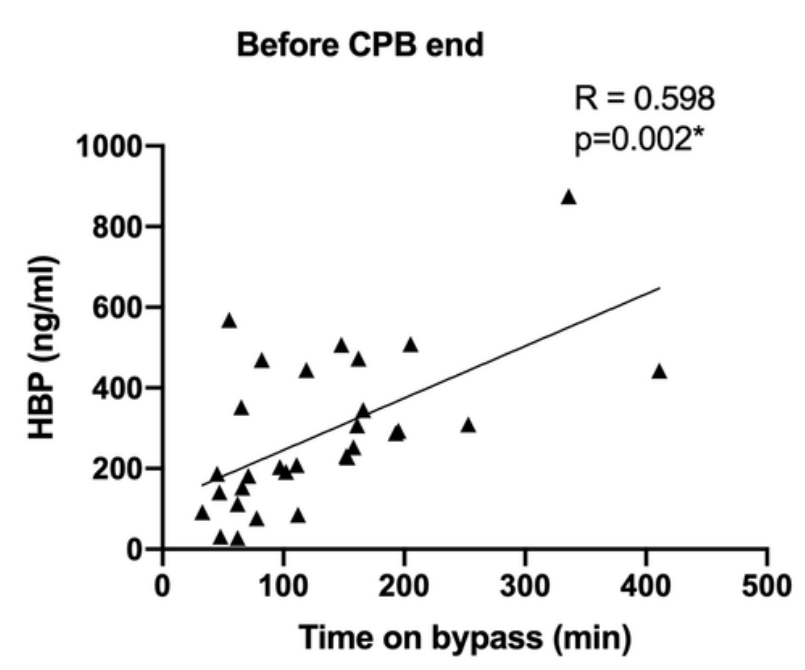

5 min after CPB end/after protamine
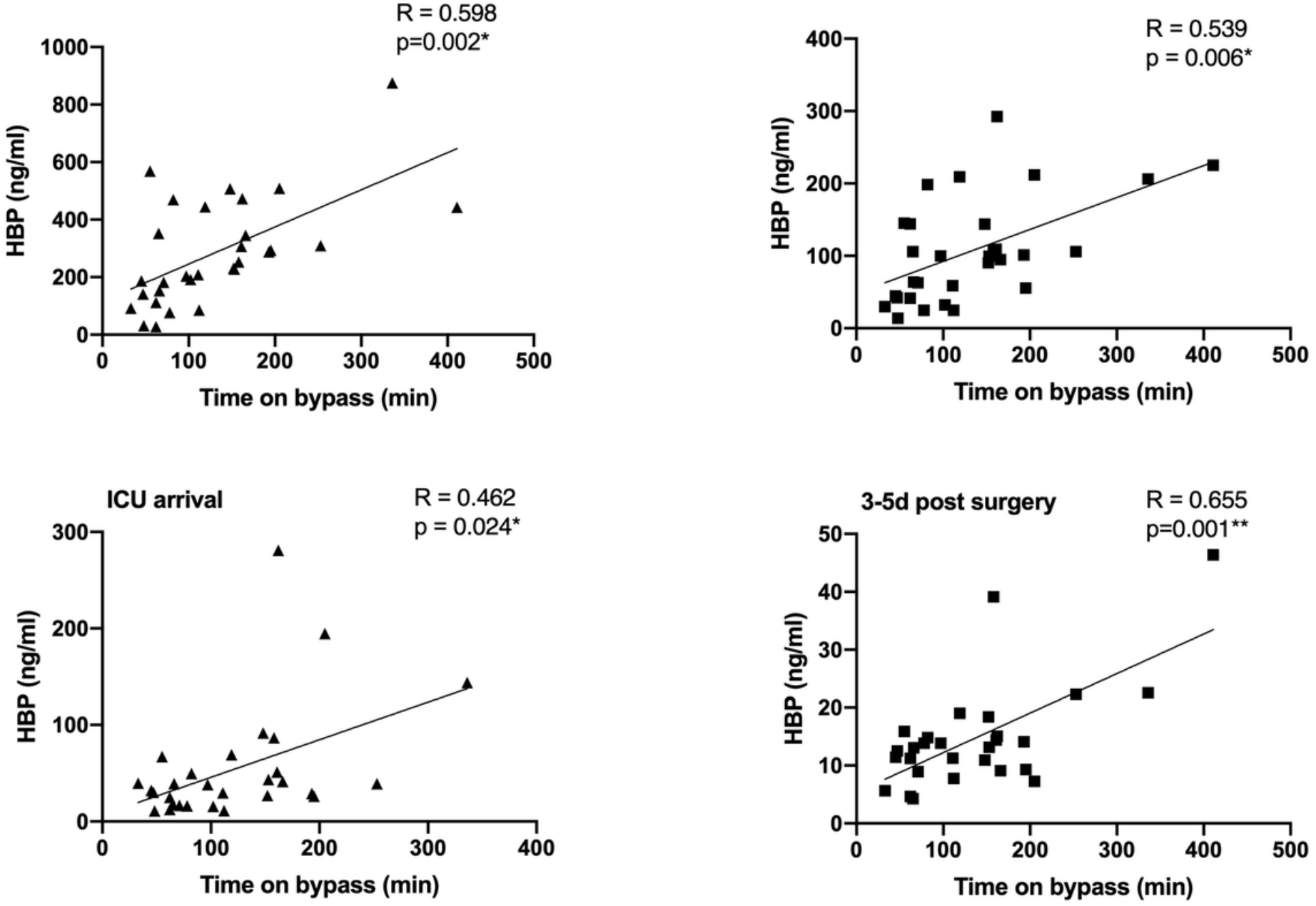

Figure 3

Spearman correlation analysis illustrating the correlation between heparin-binding protein (HBP) concentration and time on cardiopulmonary bypass (CPB). ICU: Intensive care unit. 


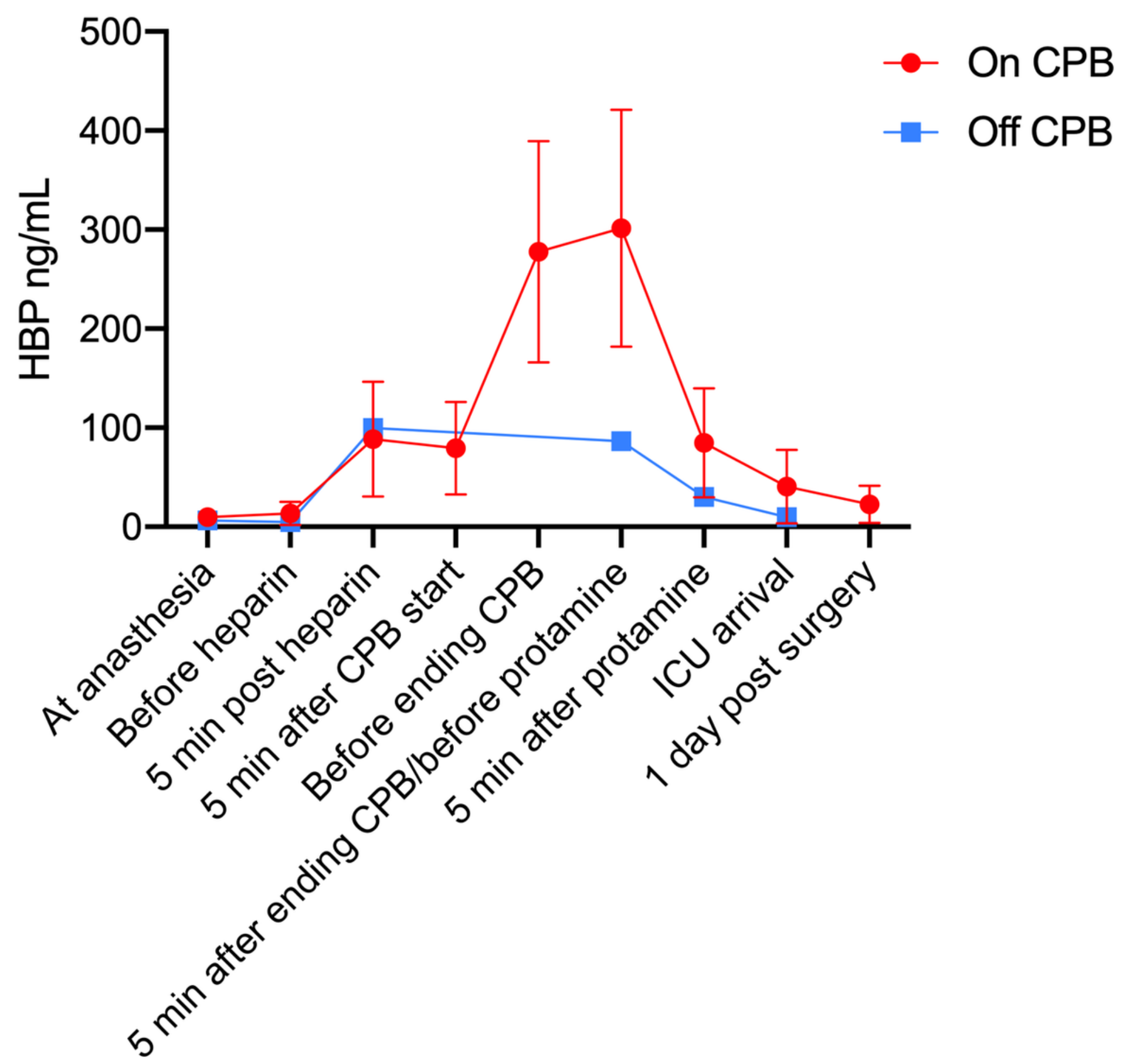

Figure 4

HBP levels in the five additional CABG patients included in the study. One patient had an ad hoc off-pump procedure due to porcelain aorta. HBP concentrations are presented as median $+/$ - interquartile range (IQR). ICU: intensive care unit. 
A)

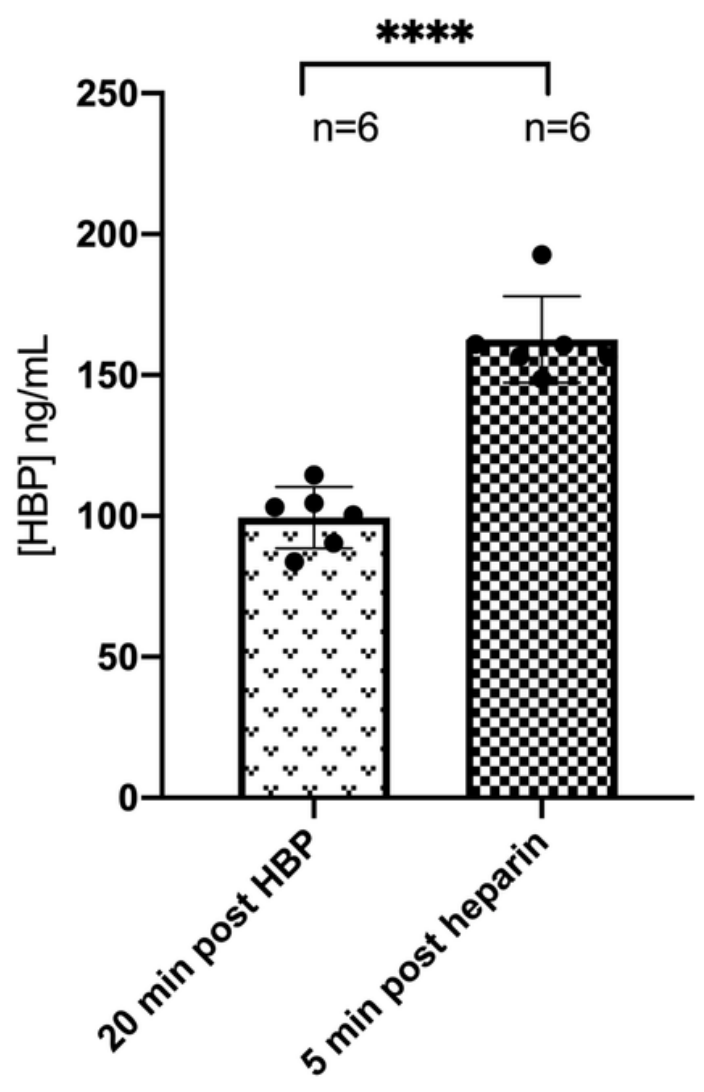

B)

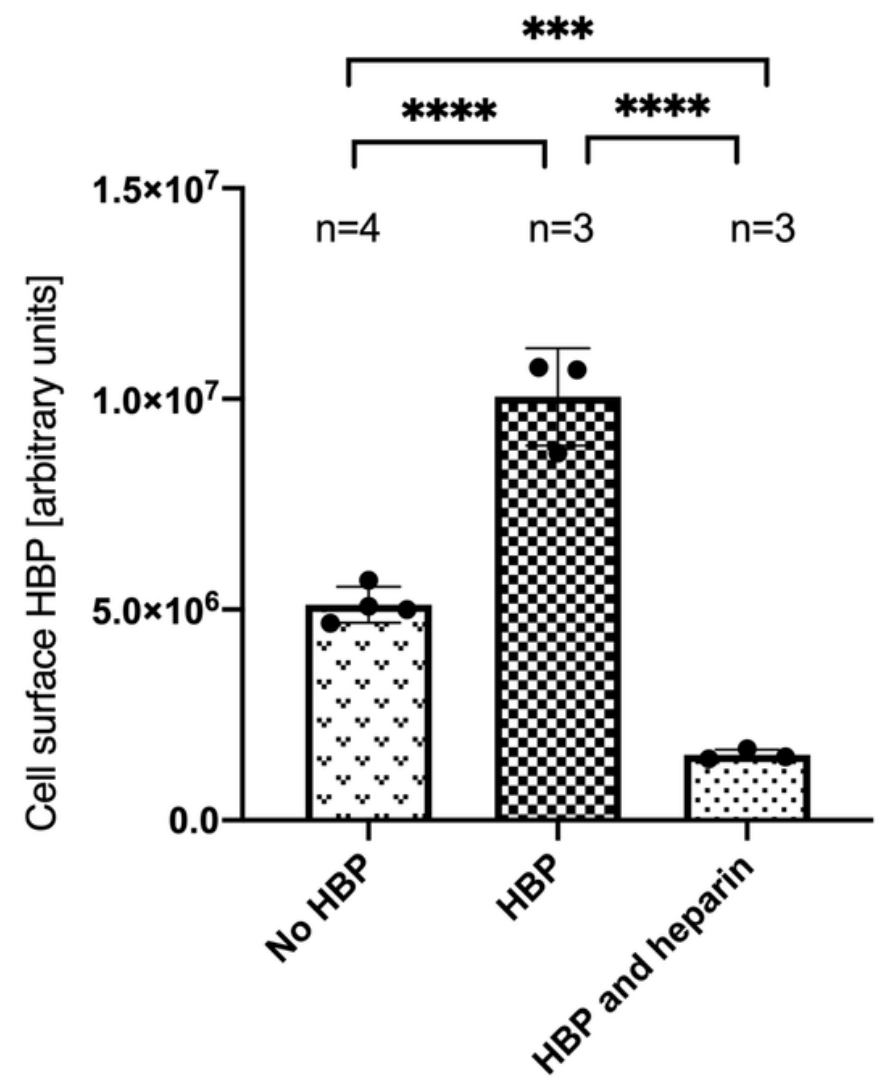

Figure 5

HBP adsorption to endothelial cell surface and its interaction with heparin. A) ELISA measuring HBP level in supernatant from treated cells, 20 min after addition of HBP and then 5 min after addition of heparin. B) Quantification of cell surface-bound HBP using CLIC before addition of HBP, 20 min after addition of HBP, and 5 min after addition of heparin. ELISA: Enzyme-linked immunosorbent assay; CLIC : Chemiluminescence imaging of cells 


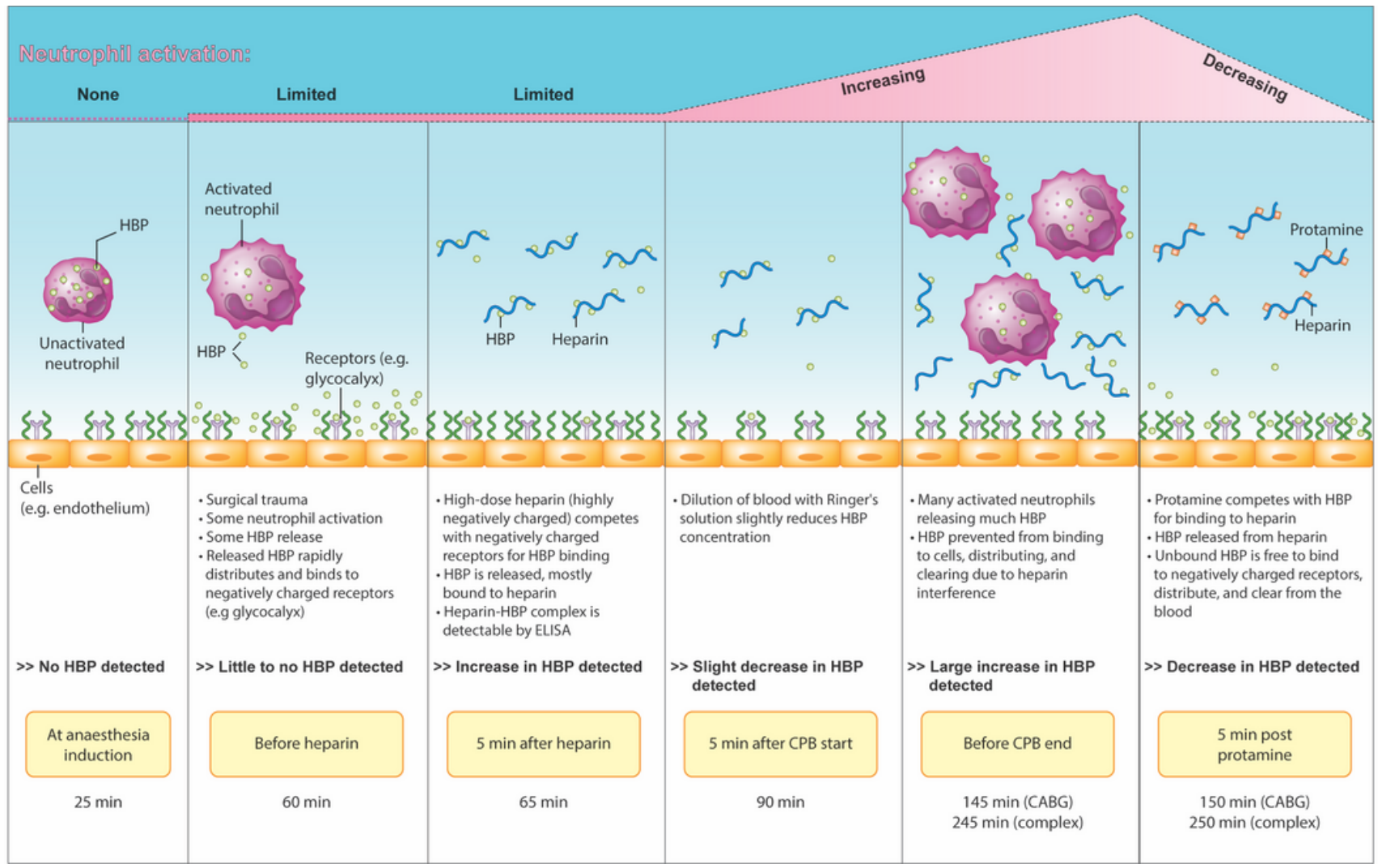

\section{Figure 6}

Graphic illustration of suggested mechanism to explain the observed changes in HBP levels throughout cardiac surgery with $\mathrm{CPB}$

\section{Supplementary Files}

This is a list of supplementary files associated with this preprint. Click to download.

- GraphicalabstractCC.png

- GraphicalabstractCC.png

- SupplmaterialCC.docx

- SupplmaterialCC.docx 